\title{
Ethanol Production Potential of Ethanol-Tolerant Saccharomyces and Non-Saccharomyces Yeasts
}

\author{
SUTTICHA NA-RANONG THAMMASITTIRONG ${ }^{1 \star}$, THADA CHAMDUANG ${ }^{1}$, UMAPORN PHONROD 2 \\ and KLANARONG SRIROTH ${ }^{3}$ \\ ${ }^{1}$ Department of Founding Project of Microbiology, Faculty of Liberal Arts and Science, \\ Kasetsart University Kamphaeng Saen Campus, Nakorn Pathom, Thailand \\ ${ }^{2}$ Department of Science, Faculty of Liberal Arts and Science, Kasetsart University Kamphaeng Sean Campus, \\ Nakorn Pathom, Thailand \\ ${ }^{3}$ Department of Biotechnology, Faculty of Agro-industry, Kasetsart University, Bangkok, Thailand
}

Received 2 April 2012, revised 11 June 2012, accepted 4 July 2012

Abstract

Four ethanologenic ethanol-tolerant yeast strains, Saccharomyces cerevisiae (ATKU132), Saccharomycodes ludwigii (ATKU47), and Issatchenkia orientalis (ATKU5-60 and ATKU5-70), were isolated by an enrichment technique in yeast extract peptone dextrose (YPD) medium supplemented with $10 \%(\mathrm{v} / \mathrm{v})$ ethanol at $30^{\circ} \mathrm{C}$. Among non-Saccharomyces yeasts, Sd. ludwigii ATKU47 exhibited the highest ethanoltolerance and ethanol production, which was similar to S. cerevisiae ATKU132. The maximum range of ethanol concentrations produced at $37^{\circ} \mathrm{C}$ by S. cerevisiae ATKU132 and Sd. ludwigii ATKU47 from an initial D-glucose concentration of 20\% (w/v) and 28\% (w/v) sugarcane molasses were $9.46-9.82 \%(\mathrm{w} / \mathrm{v})$ and $8.07-8.32 \%(\mathrm{w} / \mathrm{v})$, respectively.

Ke y w ord s: ethanol production, ethanol-tolerant, Saccharomyces yeast, non-Saccharomyces yeast

In recent years, ethanol used as a fuel, has become increasingly important because it is a renewable and environmentally friendly resource. The major requirements of industrial fuel ethanol production are high ethanol yield and low-cost production. Effective ethanol production depends on yeast fermentation capability and the ability to grow under industrial conditions, such as ethanol accumulation, high temperature, low $\mathrm{pH}$ and osmotic pressure from product and substrate sugars (Blieck et al., 2007, Zhao and Bai, 2009). Among various stresses, ethanol concentration is the most important stress factors that can not be avoided during fermentation (Querol et al., 2003). High ethanol concentration is well known to inhibit cell growth and viability (Pina et al., 2004). Multiple study performed to date, focused interest on ethanol tolerance in yeasts based on the presumption that ethanol-tolerant yeast strains would have enhanced ethanol productivity and yield, and such strains can be used for the production of economically viable industrial fuel ethanol (Basso et al., 2008, Hu et al., 2007, Shi et al., 2009).
In this study, we describe the screen for ethanologenic and ethanol-tolerant yeast strains from environmental samples. We also tested the capability of the selected yeast strains to produce ethanol from D-glucose and carbon substrates from sugarcane molasses and yeast cell viability in ethanol.

We assumed that soil samples in long-term exposure to ethanol might contain ethanol-tolerant microorganisms. To confirm this, soil samples from the drainage area of a winery at Kasetsart University, Kamphaeng Saen Campus were collected and enriched in YPD ( $1 \%$ yeast extract, $2 \%$ peptone, $2 \% \mathrm{D}$-glucose) medium supplemented with $10 \%(\mathrm{v} / \mathrm{v})$ ethanol for $48-72 \mathrm{~h}$ at $30^{\circ} \mathrm{C}$, and then plated onto YPD agar supplemented with $10 \%(\mathrm{v} / \mathrm{v})$ ethanol using spread-plate technique. Each isolated ethanol-tolerant strain was grown in medium supplemented with $10 \%(\mathrm{v} / \mathrm{v})$ ethanol in a test tube containing a Durham tube and incubated at $30^{\circ} \mathrm{C}$ for $72 \mathrm{~h}$. The strains showing an accumulation of $\mathrm{CO}_{2}$ gas in the Durham tubes were selected for screening for high ethanol-production in fermentative (FM) medium

* Corresponding author: S.N.-R. Thammasittirong, Department of Founding Project of Microbiology, Faculty of Liberal Arts and Science, Kasetsart University, Kamphaeng Saen Campus, Nakorn Pathom, 73140, Thailand; phone: +663-428-1105; fax: +663-428-1057; e-mail: sutticha.n@ku.ac.th 


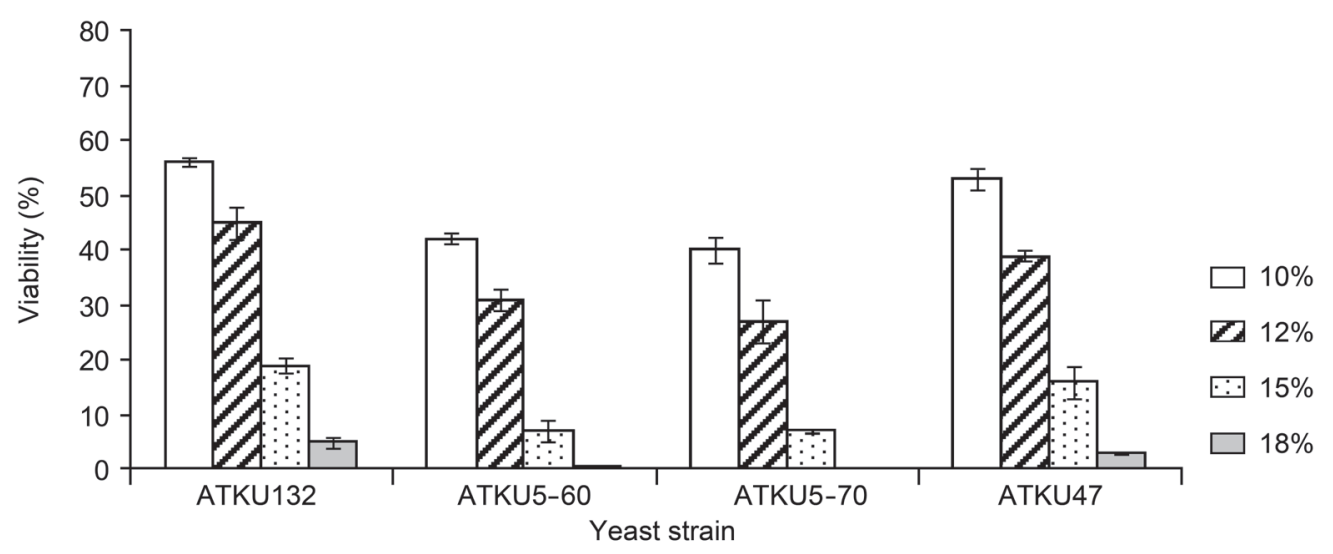

Fig. 1. Effect of increasing ethanol concentration on cell viability of the four selected ethanol-tolerant yeasts. Ethanol concentrations are given in $\%(v / v)$. Viability at each ethanol concentration is expressed as the \% of the colony-forming units for the stress treatments compared with the untreated condition

(1\% yeast extract, $2 \%$ peptone, $10 \%$ D-glucose, $0.6 \%$ $\left(\mathrm{NH}_{4}\right)_{2} \mathrm{SO}_{4}, 0.15 \% \mathrm{KH}_{2} \mathrm{PO}_{4}, \mathrm{pH} 5.5$ ) (Shi et al., 2009) at $30^{\circ} \mathrm{C}$ with shaking at $100 \mathrm{rpm}$ for $48 \mathrm{~h}$. The ethanol concentration was analyzed by gas chromatography (GC) (Chrompack CP9001, Chrompack, The Netherlands) equipped with a capillary column type CP WAX 52 CB (Chrompack, The Netherlands) and fitted with a flame ionization detector. The temperature of the detector and injector were $275^{\circ} \mathrm{C}$ and $250^{\circ} \mathrm{C}$, respectively.

The selected ethanologenic ethanol-tolerant yeasts were identified by rDNA sequence analysis. The DNA region containing the D1/D2 domain of the $26 \mathrm{~S}$ rRNA gene was amplified using the universal fungal primer pairs NL1 and NL4 (O’Donnell, 1993). PCR products were sequenced and compared with the sequences from the GenBank database using the BLAST tool (www. ncbi.nlm.nih.gov/BLAST/).

The viability of yeast cells in ethanol was tested in a medium containing ethanol. Yeast cells were grown in YPD medium at $30^{\circ} \mathrm{C}$ and were collected in log-phase of growth, cells were washed twice with YPD medium and then were transferred to YPD medium with $10-18 \%(\mathrm{v} / \mathrm{v})$ ethanol and without ethanol as a control (final density $2 \times 10^{6}$ cells $/ \mathrm{ml}$ ). The cultures were incubated at $30^{\circ} \mathrm{C}$ with shaking at $100 \mathrm{rpm}$ for $36 \mathrm{~h}$. Serial dilutions of each yeast culture were plated on YPD agar and incubated at $30^{\circ} \mathrm{C}$ for $72 \mathrm{~h}$.

Among the 82 tested ethanol-tolerant yeast strains, four ethanologenic ethanol-tolerant strains - ATKU132, ATKU47, ATKU5-60, and ATKU5-70, were selected for further studies. The strains exhibited the highest ethanol production (5-6\% w/v), in FM medium containing $10 \%(\mathrm{w} / \mathrm{v}) \mathrm{D}$-glucose when grown at $30^{\circ} \mathrm{C}$ for $48 \mathrm{~h}$. Based on the results of the BLAST comparison, the four ethanologenic ethanol-tolerant yeasts can be classified into two groups, Saccharomyces (Saccharomyces cerevisiae ATKU132) yeast and non-Saccharomyces yeasts (Saccharomycodes ludwigii ATKU47, and Issa- tchenkia orientalis ATKU5-60 and ATKU5-70). S. cerevisiae is one of the best known microorganisms used for industrial ethanol fermentation. This yeast exhibits higher ethanol tolerance than ethanol-producing bacteria and non-Saccharomyces yeasts (Ciani and Picciotti, 1995). Species of non-Saccharomyces yeasts generally are not tolerant to ethanol concentrations exceeding 5-6\% (v/v) (Fleet, 2003, Gil et al., 1996). The results of ethanol tolerance test revealed that the isolated nonSaccharomyces yeasts could survive in media containing 10-15\% (v/v) ethanol (Fig. 1). When yeast cells were exposed to $18 \%(\mathrm{v} / \mathrm{v}$ ) ethanol, S. cerevisiae ATKU132 and Sd.ludwigii ATKU47 exhibited cell viability in the range of 3-5\%, while the others lost their viability. This is in an agreement with several reports which suggest that various species of non-Saccharomyces yeast, such as Hanseniaspora, Candida, Saccharomycodes and Zygosacchromyces, may have tolerance similar to the Saccharomyces species (Fleet, 2008; Pina et al., 2004).

In addition, we found a correlation between cell viability and fermentation capability. The highest ethanoltolerant strains, S. cerevisiae ATKU132 and Sd. ludwigii ATKU47 were producing ethanol with the highest efficiency. Table I presents the results of ethanol production in a medium containing $20 \%$ (w/v) D-glucose at $37^{\circ} \mathrm{C}$ with aeration (shaking), which is the commonly used temperature during ethanol fermentation in a tropical country. Maximal ethanol concentration produced by $S d$. ludwigii ATKU47 was $9.82 \pm 0.14 \%$ (w/v), productivity of $1.64 \pm 0.02 \mathrm{~g} / \mathrm{l} / \mathrm{h}$ and a theoretical yield of $96.05 \%$. The same values for S. cerevisiae ATKU132 were $9.46 \pm 0.16 \%(\mathrm{w} / \mathrm{v}), 1.31 \pm 0.02 \mathrm{~g} / \mathrm{l} / \mathrm{h}$ and $92.56 \%$, respectively.

Based on the ability to utilize and ferment D-sucrose of S. cerevisiae ATKU132 and Sd.ludwigii ATKU47 (data not shown), these yeast strains were selected to test their abilities to ferment sugarcane molasses, a by-product of sugar manufacturing, which con- 
Table I

Ethanol fermentation by the ethanologenic ethanol-tolerant strains in 20\% (w/v) D-glucose and 28\% (w/v) sugarcane molasses at $37^{\circ} \mathrm{C}$ for $72 \mathrm{~h}$

\begin{tabular}{|c|c|c|c|c|c|c|}
\hline \multirow[b]{2}{*}{ Strain } & \multicolumn{3}{|c|}{$20 \%(\mathrm{w} / \mathrm{v}) \mathrm{D}$-glucose } & \multicolumn{3}{|c|}{$28 \%(\mathrm{w} / \mathrm{v})$ sugarcane molasses } \\
\hline & $\begin{array}{l}\text { Ethanol }^{1} \\
\%(w / v)\end{array}$ & $\begin{array}{c}\text { Productivity } \\
(\mathrm{g} / \mathrm{l} / \mathrm{h})\end{array}$ & $\begin{array}{c}\text { Theoretical } \\
\text { yield (\%) }\end{array}$ & $\begin{array}{l}\text { Ethanol }^{1} \\
\%(w / v)\end{array}$ & $\begin{array}{c}\text { Productivity } \\
(\mathrm{g} / \mathrm{l} / \mathrm{h})\end{array}$ & $\begin{array}{c}\text { Theoretical } \\
\text { yield (\%) }\end{array}$ \\
\hline S. cerevisiae ATKU132 & $\begin{array}{c}9.46 \pm 0.16^{c} \\
(72 \mathrm{~h})\end{array}$ & $1.31 \pm 0.02^{\mathrm{b}}$ & $92.56^{c}$ & $\begin{array}{c}8.07 \pm 0.10^{\mathrm{a}} \\
(72 \mathrm{~h})\end{array}$ & $1.12 \pm 0.03^{\mathrm{a}}$ & $92.67^{\mathrm{a}}$ \\
\hline Sd. ludwigii ATKU47 & $\begin{array}{c}9.82 \pm 0.14^{\mathrm{c}} \\
(60 \mathrm{~h})\end{array}$ & $1.64 \pm 0.02^{\mathrm{d}}$ & $96.05^{\mathrm{d}}$ & $\begin{array}{c}8.32 \pm 0.07^{\mathrm{a}} \\
(72 \mathrm{~h})\end{array}$ & $1.15 \pm 0.02^{\mathrm{a}}$ & $95.54^{\mathrm{b}}$ \\
\hline I. orientalis ATKU5-60 & $\begin{array}{c}8.27 \pm 0.30^{\mathrm{b}} \\
(60 \mathrm{~h})\end{array}$ & $1.38 \pm 0.05^{c}$ & $80.93^{\mathrm{b}}$ & n.a. & n.a. & n.a. \\
\hline I. orientalis ATKU5-70 & $\begin{array}{c}7.30 \pm 0.23^{\mathrm{a}} \\
(60 \mathrm{~h})\end{array}$ & $1.22 \pm 0.04^{\mathrm{a}}$ & $71.43^{\mathrm{a}}$ & n.a. & n.a. & n.a. \\
\hline
\end{tabular}

Results with the same letter are not significantly different $(p<0.05)$

${ }^{1}$ The time points indicate the maximum ethanol concentrations producing by the yeast strains.

* The following theoretical values have been used for calculation (g ethanol/g sugar): sucrose, 0.538 ; maltose, 0.538 ; glucose, 0.511 ; fructose, 0.511 ; maltotriose, 0.548 . The values of composition of fermentable sugars in molasses $(78 \%(\mathrm{w} / \mathrm{v}))$ have been used for calculation $(\% \mathrm{w} / \mathrm{w})$ : sucrose, 34.6 ; fructose, 13.5; glucose, 10.4; maltose, 0.11 ; maltotriose, 0.45 . Theoretical yield of undiluted molasses $=0.311 \mathrm{~g} / \mathrm{g}$ molasses.

n.a. - not analyzed

tains sucrose as a major fermentable sugar. Results presented in Table I show that S. cerevisiae ATKU132 and Sd.ludwigii ATKU47 were able to produce high amounts of ethanol from sugarcane molasses medium (28\% soluble solid, $0.05 \%\left(\mathrm{NH}_{4}\right)_{2} \mathrm{SO}_{4}, 0.05 \% \mathrm{KH}_{2} \mathrm{PO}_{4}$, $\left.0.05 \% \mathrm{MgSO}_{4} \cdot 7 \mathrm{H}_{2} \mathrm{O}, \mathrm{pH} 5.3\right)$. The amount of ethanol produced by S. cerevisiae ATKU132 and Sd.ludwigii ATKU47 were $8.07 \%(\mathrm{w} / \mathrm{v})$ and $8.32 \%(\mathrm{w} / \mathrm{v})$, respectively.

In summary, the results of this study indicated that the newly isolated ethanol-tolerant yeasts, especially S. cerevisiae ATKU132 and Sd.ludwigii ATKU47, are excellent strains that are promising candidates for large-scale ethanol production from sugarcane waste by-products. Further evaluation of these strains under scaled-up conditions and strain improvement for increasing ethanol yield are planned for future study.

\section{Acknowledgements}

This research was financially supported by the Thailand Research Fund (TRF) and The Commission on Higher Education (CHE), Thailand. We are very much indebted to Dr. Donald A. MacKenzie, Institute of Food Research, Norwich, UK, for his critical comments.

\section{Literature}

Basso L.C., H.V. De Amorim, A.J. De Oliveira and M.L. Lopes. 2008. Yeast selection for fuel ethanol production in Brazil. FEMS Yeast Research. 8: 1155-1163.
Blieck L., G. Toye, F. Dumortier, K.J. Verstrepen, F.R. Delvaux, J.M. Thevelein and P. Van Dijck. 2007. Isolation and characterization of brewer's yeast variants with improved fermentation performance under high-gravity conditions. Appl. Environ. Microbiol. 73: 815-824.

Ciani M. and G. Picciotti. 1995. The growth kinetics and fermentation behaviour of some non-Saccharomyces yeasts associated with wine-making. Biotechnol. Lett. 17: 1247-1250.

Fleet G.H. 2003. Yeast interactions and wine flavour. Int. J. Food Microbiol. 86: 11-22.

Fleet G.H. 2008. Wine yeasts for the future. FEMS Yeast Res. 8: 979-995.

Gil J.V., J.J. Mateo, M. Jiménez, A. Pastor and T. Huerta. 1996. Aroma compounds in wine as influenced by apiculate yeasts. J. Food Sci. 61: 1247-1250.

Hu X.H., M.H. Wang, T. Tan, J.R. Li, H. Yang, L. Leach, R.M. Zhang and Z.W. Luo. 2007. Genetic dissection of ethanol tolerance in the budding yeast Saccharomyces cerevisiae. Genetics. 175: 1479-1487. O'Donnell K. 1993. Fusarium and its near relatives, in The fungal holomorph: mitotic, meiotic and pleomorphic speciation in fungal systematics, Eds. D.R. Reynolds and J.W. Taylor, CAB International: Wallingford. p. 225-233.

Pina C., J.A. Couto and T. Hogg. 2004. Inferring ethanol tolerance of Saccharomyces and non-Saccharomyces yeasts by progressive inactivation. Biotechnol. Lett. 26: 1521-1527.

Querol A., M.T. Fernandez-Espinar, M. del Olmo and E. Barrio. 2003. Adaptive evolution of wine yeast. Int. J. Food Microbiol. 86: $3-10$.

Shi D.J., C.L. Wang and K.M. Wang. 2009. Genome shuffling to improve thermotolerance, ethanol tolerance and ethanol productivity of Saccharomyces cerevisiae. J. Ind. Microbiol. Biotechnol. 36: 139-147. Zhao X.Q. and F.W. Bai. 2009. Mechanisms of yeast stress tolerance and its manipulation for efficient fuel ethanol production. J. Biotechnol. 144: 23-30. 